\title{
Elevation of Neutrophil Elastase Activity in Intra-Operative Recovered Shed Blood
}

Soichi Maekawa, Kensuke Umakoshi, Satoshi Kikuchi, Hironori Matsumoto, Jun Takeba, Suguru Anen, Naoki Moriyama and Mayuki Aibiki ${ }^{\star}$ Department of Emergency and Critical Care Medicine, Graduate School of Medicine, Ehime University, Japan

\begin{abstract}
Background and Aim: Neutrophil elastase releasing from activated polymorphonuclear neutrophils (PMN) may have a central role in acute lung injury. Thus, we examined whether neutrophil elastase activity (NEA), a crucial parameter for organ damages from stresses, may increase in intra-operative recovered blood and also whether the storage duration of the bank bloods may affect such changes in NEA.

Methods: In thirty-two packed red cells of bank bloods, NEAs were measured by ELISA on several day points after the storage. Intra-operative salvaged red cell concentrates (RCCs) were obtained from thirteen patients undergoing spinal surgery. The salvaged bloods from the patients were divided into two groups: NE activities in autologous RCCs obtained from eight patients were examined soon after the preparation (Group A); such activities in RCCs from five subjects were determined post-operatively (Group B).

Results: In the bank bloods, NEAs gradually increased after the storage, showing a plateau at the day 10 if not specifically filtered leukocytes before the preparation. In Group B, NEA levels in RCCs were significantly higher than those in Group A. In Group B (RCCs stored for four hours), NEAs were nearly two times higher than those of the peak NEA values of the bank blood at the day 21 .
\end{abstract}

Conclusion: Thus, we need to pay attention the occurrence of lung injury even after the transfusion of autologous bloods collecting by the intra-operative shed blood recovered system.

Keywords: Neutrophil Elastase Activity; Shed Blood; Red cell concentrates

\section{Background}

Autologous blood transfusion is widely performed for the purpose of reducing the possible adverse reactions, such as transfusionrelated acute lung injury (TRALI) from allogeneic transfusion [1]. Intra-operative blood salvage system is a tool for the autologous blood transfusion [2], but the preparation in the system might cause hematological changes in the salvaged bloods. However, there is the limited information regarding such as mediator changes in recovered blood collecting through the system.

Polymorphonuclear neutrophils (PMNs) may be involved in the development of lung injury after allogeneic transfusion [3]. Furthermore, neutrophil elastase (NE) releasing from activated PMNs may have a central role in the acute lung injury (ALI) [4]. Therefore, we examined whether neutrophil elastase activity (NEA), a crucial mediator activity for organ damages after stress situations, may increase in intra-operative recovered blood and also whether the storage duration of bank bloods may affect such changes in NEA.

\section{Subjects and Methods}

Bank red cell concentrates (RCCs): In thirty-two banked packed red cells provided from the Japan Red Cross Society, NEAs were measured on $3,5,10,14,21$ days after the standard storage keeping at $4^{\circ} \mathrm{C}$. Eight RCCs were stored for 10, 14, 21 days after the filtering of white blood cells (WBCs) to evaluate the effects of leukocytes on NEA changes in salvaged bloods. Intra-operative salvaged RCCs were obtained from fourteen patients undergoing spinal surgery in the operating theater. The salvaged bloods from the patients were divided into two groups: $\mathrm{NE}$ activities in autologous RCCs from eight patients were measured soon after the preparation (Group A: Table 1); such activities in RCCs from six subjects were determined post-operatively (Group B: Table 2). In Group A, bloods were salvaged from shed blood at the room temperature and transfused during the operation; In Group B, those were recovered also during the operation and infused to be stored at the room temperature four hours after the operation.

Inclusion criteria for this study: adult patients of 20 to 80 years of age undergoing spinal operation using a shed blood recovery system. Exclusion criteria: patients who have severe complications such as diabetes mellitus and organ abnormal functions including coagulopathy. Neutrophil elastase activities (NEA) in the bank and salvaged bloods were measured by ELISA (Mitsubishi Chemical Medicine Co., Ltd. Tokyo JAPAN). The NEA is measured as the concentration of complex of neutrophil elastase combined with alpha 1-antitrypsin. Statistical analysis was done by Mann-Whitney U-test or ANOVA with Scheffe's F-test $(\mathrm{p}<0.05)$ as appropriate. This study has been approved to use blood samples obtained from patients in this study by the IRB of Ehime University Hospital (EHIME UNIV IRB, Approvable \#1410020).

\section{Results}

In the bank bloods, NEAs increased remarkably at ten days after the storage if not specifically pre-filtered WBCs (Figure 1).

There are no differences in the demographic data between the two

*Corresponding author: Mayuki Aibiki, Department of Emergency and Critical Care Medicine, Graduate School of Medicine, Ehime University, Shitsukawa 454, Tohon, Ehime, 791-0295, Japan, Tel: +81-89-960-5722; Fax: +81-89-960-5714; Email: aibiki@m.ehime-u.ac.jp

Received July 28, 2014; Accepted October 29, 2014; Published November 25 2014

Citation: Maekawa S, Umakoshi K, Kikuchi S, Matsumoto H, Takeba J, et al. (2014) Elevation of Neutrophil Elastase Activity in Intra-Operative Recovered Shed Blood. J Blood Disorders Transf 5: 235. doi: 10.4172/2155-9864.1000235

Copyright: (c) 2014 Maekawa S, et al. This is an open-access article distributed under the terms of the Creative Commons Attribution License, which permits unrestricted use, distribution, and reproduction in any medium, provided the original author and source are credited. 


\begin{tabular}{|c|c|c|c|c|c|c|c|}
\hline No of Case & Age & Gender & $\begin{array}{l}\mathrm{HT} / \mathrm{HW} \\
(\mathrm{cm}) /(\mathrm{kg})\end{array}$ & $\begin{array}{l}\text { Vol. of bleeding } \\
\text { (ml) }\end{array}$ & $\begin{array}{c}\text { Vol. of RCC } \\
\text { transfusion (m1) }\end{array}$ & $\mathrm{Hb}$ of RCC (g/d1) & $\begin{array}{c}\text { Timing of } \\
\text { transfusion }\end{array}$ \\
\hline 1 & 57 & Female & $147 / 60$ & 700 & 120 & 8.9 & Infra-ope. \\
\hline 2 & 51 & Male & $160 / 65$ & 1160 & 360 & 11.7 & Infra-ope. \\
\hline 3 & 65 & Female & 158M5 & 750 & 130 & 9.8 & Infra-ope. \\
\hline 4 & 57 & Male & $160 / 60$ & 800 & 220 & 12.0 & Infra-ope. \\
\hline 5 & 63 & Female & $147 / 58$ & 1200 & 350 & 19.5 & Infra-ope. \\
\hline 6 & 50 & Male & 16125 & 550 & 120 & 6.9 & Infra-ope. \\
\hline 7 & 21 & Male & $170 / 58$ & 850 & 130 & 11.7 & Infra-ope. \\
\hline 8 & 50 & Female & $150 / 42$ & 200 & 110 & 6.8 & Infra-ope. \\
\hline $\begin{array}{l}\text { Average } \\
\text { (SD) }\end{array}$ & $\begin{array}{r}51.8 \\
+13.7\end{array}$ & $\begin{array}{l}M: F \\
4: 4\end{array}$ & $\begin{array}{c}156.6 \pm 8.6 / 6 \\
0.4 \pm 9.3\end{array}$ & $776.3 \pm 321.3$ & $192.5 \pm 106.1$ & $10.9 \pm 4.0$ & \\
\hline
\end{tabular}

Table 1: Clinical characteristics of Group A patients.

\begin{tabular}{|c|c|c|c|c|c|c|c|}
\hline No. of Case & Age & Gender & $\mathrm{HT} / \mathrm{BW}(\mathrm{cm}) /(\mathrm{kg})$ & Vol. of bleeding (m1) & Vol. of RCC transfusion (m1) & $\mathrm{Hb}$ of $\mathrm{RCC}(\mathrm{g} / \mathrm{d} 1)$ & Timing of transfusion \\
\hline \multirow[t]{2}{*}{1} & 62 & Male & $169 / 72$ & 450 & 120 & 99 & Post-ope. \\
\hline & 68 & Female & $149 / 83$ & 850 & 210 & 116 & Post-ope. \\
\hline 3 & 67 & Male & $163 / 65$ & 1250 & 370 & 117 & Post-ope. \\
\hline 4 & IS & Female & $160 / 70$ & 500 & 100 & 8.6 & Post-ope. \\
\hline 5 & 71 & Male & $168 / 53$ & 300 & 120 & 103 & Post-ope. \\
\hline Average (SD) & $56.6 \pm 23.5$ & $\begin{array}{l}M: F \\
3: 2\end{array}$ & $\begin{array}{l}161.8 \pm 8.0 \\
/ 68.8 \pm 10.9\end{array}$ & $670.0 \pm 381.8$ & $184.0 \pm 289.8$ & $10.8 \pm 1.9$ & \\
\hline
\end{tabular}

Table 2: Clinical characteristics of Group B patients.

Changes of NEA levels in Packed Red Cells of Bank Blood

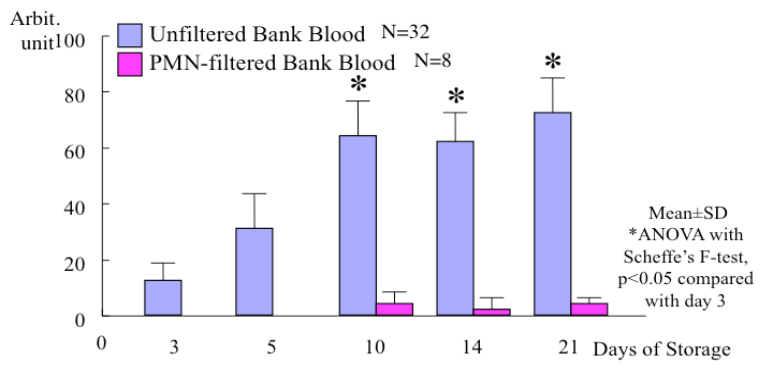

Figure 1: NEA levels in PMN unfiltered bank bloods elevated remarkably peaking on day 21. But after the filtering of leukocytes, such increases were completely suppressed.

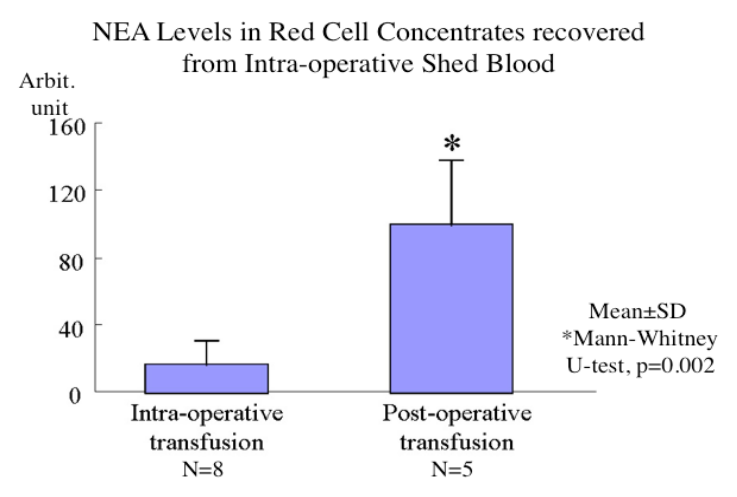

Figure 2: In Group B (post-op. transfusion), NEA levels in red cell concentrates (RCCs) were significantly higher than those in Group A (intra-op. transfusion).

groups. In Group B (RCCs stored for four hours), NEA levels in red cell concentrates (RCCs) were significantly higher than those in Group A (Figure 2). In Group B, NEA was nearly two times higher than the peak NEA value of the bank blood at the day 21 (Figures 1 and 2).

\section{Discussion}

In this study, we demonstrated the time-dependent elevation of NEAs in the bank bloods without specific filtering of WBCs, but if filtered, such elevations of NEAs were abolished, suggesting that increases in NEA in the bank bloods after the storage for at least more than ten days may be due to PMNs in the bank bloods. Furthermore, we found nearly two-times higher levels of NEAs in the intra-operative recovered autologous bloods as compared those in the bank bloods. Therefore, we need to be aware of a potential occurrence of lung injury even by the transfusion of autologous bloods collecting by the intraoperative shed blood recovered system if stored for several hours. Furthermore, there is need to test a hypothesis that a specific neutrophil elastase inhibitor [5] might have a certain preventive effect on the lung injury after transfusion of recovered shed bloods during the operation.

One might speculate that even if blood containing high levels of NE was transfused, NE would result in the complex of neutrophil elastasealpha1-antitrypsin (EAC), thereby NE was inactivated [6]. However, it was indicated that EAC itself might activate monocytes, rendering to increase in NE production in humans [7]. In fact, we have reported that in rabbits, EAC itself causes acute lung injuries [8]. Recently, it has been reported that recovered shed bloods after leukocyte filtering could be a safer method even for obstetric or infected patients who were prohibited to use this autologous salvaged blood [9]. In this regard, the present results may support this expansion of the indication of intra-operative recovered shed blood. Furthermore, future research is warranted to define the role of NE contained in the autologous intraoperative salvaged blood in patients undergoing the operation.

In conclusion, in intra-operative salvaged red cell concentrates, augmentation of NE activity occurred. Especially such changes were prominent if stored even for several hours. These results suggest that autologous transfusion of intra-operative salvaged blood should be administered soon after the preparation for preventing potential lung injuries. This concept supports the statement of the autologous blood transfusion guidance [10]. A recent review for TRALI indicated that non-antibody mediated lung injuries might be due to cell derived 
Citation: Maekawa S, Umakoshi K, Kikuchi S, Matsumoto H, Takeba J, et al. (2014) Elevation of Neutrophil Elastase Activity in Intra-Operative Recovered Shed Blood. J Blood Disorders Transf 5: 235. doi: 10.4172/2155-9864.1000235

Page 3 of 3

substances in donor blood after storage [11], so in the future, we need to clarify definitive causes of TRALI and seek a better method for blood preservation.

\section{References}

1. Silliman CC, Boshkov LK, Mehdizadehkashi Z, Elzi DJ, Dickey WO, et al. (2003) Transfusion-related acute lung injury: epidemiology and a prospective analysis of etiologic factors. Blood 101: 454-462.

2. Waters JH, Dyga RM, Waters JF, Yazer MH (2011) The volume of returned red blood cells in a large blood salvage program: where does it all go? Transfusion 51: 2126-2132.

3. Silliman CC, Curtis BR, Kopko PM, Khan SY, Kelher MR, et al. (2007) Donor antibodies to HNA-3a implicated in TRALI reactions prime neutrophils and cause PMN-mediated damage to human pulmonary microvascular endothelial cells in a two-event in vitro model. Blood 109: 1752-1755.

4. Kawabata K, Hagio T, Matsuoka S (2002) The role of neutrophil elastase in acute lung injury. Eur J Pharmacol 451: 1-10.

5. Miyoshi S, Hamada H, Ito R, Katayama H, Irifune K, et al. (2013) Usefulness of a selective neutrophil elastase inhibitor, sivelestat, in acute lung injury patients with sepsis. Drug Des Devel Ther 7: 305-316.
6. Neumann S, Gunzer G, Hennrich N, Lang H (1984) "PMN-elastase assay" enzyme immunoassay for human polymorphonuclear elastase complexed with alpha 1-proteinase inhibitor. J Clin Chem Clin Biochem 22: 693-697.

7. Nishiyama T, Aibiki M, Hanaoka K (1996) The effect of ulinastatin, a human protease inhibitor, on the transfusion-induced increase of plasma polymorphonuclear granulocyte elastase. Anesth Analg. 82: 108-112.

8. Umegaki O, Aibiki M (1996) Lung injuries due to Neutrophil Elastase-alpha-1Antitrypsin Complex (EAC) in Rabbits. ICU and CCU 20: 599-604.

9. Ashworth A, Klein AA (2010) Cell salvage as part of a blood conservation strategy in anaesthesia. Br J Anaesth 105: 401-416.

10. (2007) Guidance for standards for perioperative autologous blood collection and administration, (3rd Edn), AABB.

11. Peters AL, van Hezel ME, Juffermans NP, Vlaar AP (2014) Pathogenesis of non-antibody mediated transfusion-related acute lung injury from bench to bedside. Blood Rev 